\title{
Proceeding
}

8th INSHS International Christmas Sport Scientific Conference, 5-7 December 2013. International Network of Sport and Health

Science. Szombathely, Hungary

\section{Caffeine effect on extending time to exhaustion}

\author{
JÁN NAMEŠANSKÝ , IVA HRNČIŘIKKOVÁ, ONDŘEJ SMOLKA \\ Faculty of Sport Studies, Masaryk University Brno, Czech Republic
}

\begin{abstract}
Namešanský, J., Hrnčiříková, I. \& Smolka, O. (2014). Caffeine effect on extending time to exhaustion. J. Hum. Sport Exerc., 9(Proc1), pp.S504-S511. The purpose of this study was to determine the effect of different doses of caffeine on extending time to exhaustion in long-term endurance exercise. Using a placebo-controlled, double-blind crossover study design, 10 hobby male cyclists $(30.3 \pm 5.8 \mathrm{y}$; BMI $=23.5$ $\pm 1.6, \mathrm{VO} 2 \mathrm{max}=56.9 \pm 6.6 \mathrm{ml} \mathrm{k} \mathrm{kg}^{-1} \times \mathrm{min}^{-1}$ ) completed three experimental tests. Each test consisted of 1h steady-state cycling on static ergometer at $70 \%$ VO2max load immediately followed by graded exercise test to exhaustion $\left(2.3 \mathrm{~W} \mathrm{x} \mathrm{s}^{-1}\right)$. Either placebo or 0 or $7 \mathrm{mg} \mathrm{x} \mathrm{kg}^{-1} \mathrm{BM}$ of synthetic caffeine with $0.5 \mathrm{I}$ water and maximum of $0.5 \mathrm{mg} \mathrm{x} \mathrm{kg}^{-1} \mathrm{BM}$ of carbohydrate gel were administered 70 minutes prior to the test. Total exercise time was significantly $(p<0.05)$ extended by the $7 \mathrm{mg} \mathrm{x} \mathrm{kg}^{-1} \mathrm{BM}$ of caffeine compared with placebo. Significant $(p<0.05)$ extension of total exercise time was observed also by the $7 \mathrm{mg} \mathrm{x} \mathrm{kg}^{-1}$ compared with $2 \mathrm{mg} \mathrm{x} \mathrm{kg}^{-1}$. No statistically $(p=0.97$ ) significant differences were observed between $2 \mathrm{mg} \mathrm{x}$ $\mathrm{kg}^{-1}$ compared with placebo. Positive effect of caffeine on long-term endurance in hobby cyclist was observed only after ingestion of high dosage $\left(7 \mathrm{mg} \mathrm{x} \mathrm{kg}^{-1} \mathrm{BM}\right)$. Low dosage $\left(2 \mathrm{mg} \mathrm{x} \mathrm{kg}^{-1}\right)$ didn't show any ergogenic effect compared with placebo. This result might not be generalized, but rather shows ambiguous effects of this substance. Key words: ENDURANCE PERFORMANCE, CYCLING, NUTRITION SUPPLEMENTS.
\end{abstract}

Corresponding author. Faculty of Sport Studies, Masaryk University Brno, Czech Republic

E-mail:343664@mail.muni.cz

8th INSHS International Christmas Sport Scientific Conference, 5-7 December 2013. International Network of Sport and Health Science. Szombathely, Hungary.

JOURNAL OF HUMAN SPORT \& EXERCISE ISSN 1988-5202

(c) Faculty of Education. University of Alicante

doi:10.14198/jhse.2014.9.Proc1.39 


\section{INTRODUCTION}

Caffeine $(1,3,7$ - trimethylxanthine) is probably the most widely used stimulant substance in the world (Maughan, 2006). As a brew based on coffee beans this drug has been used since prehistoric times, thus gaining its socially acceptable status (Jeukendrup \& Gleeson, 2010).

Caffeine is naturally found in 63 species of plants and thus in various dishes and drinks. Notable plant sources of caffeine include coffee and cocoa beans, cola nuts, tea leaves, guarana berries, holly and yerba mate (Jeukendrup \& Gleeson, 2010).

Up to $75 \%$ of caffeine consumption is attributed to coffee consumption (Jeukendrup \& Gleeson, 2010) and $90 \%$ of the adult population consumes caffeine regularly (AIS Sports Nutrition, 2012). In the USA, the average caffeine consumption is $200 \mathrm{mg}$ per day, which is equivalent to about two cups of coffee, with $10 \%$ of the population receiving more than $1000 \mathrm{mg}$ per day (Greenwood et al., 2008).

The total concentration of caffeine in various foods varies greatly based on several factors: the type of plant, the amount of the source used, preparation, producer, etc. (Lieberman, 2003).

Caffeine as an ergogenic agent is used not only by the general population, but despite having virtually no energy value its use is becoming more and more popular in the racing sport too (Sokmen et al., 2008).

\section{Mechanism of effects}

Having multiple effects, caffeine is generally used for its stimulatory effect. Effects of caffeine on the body include:

- positive impact on cognitive functions via modulation of the putative inhibitory neurotransmitter adenosine (Liberman, 2003)

- an increase in cyclic adenosine monophosphate (CAMP), release of adrenaline and the resulting CNS stimulation and cardiac muscle and lipolysis stimulation (Burke \& Deakin, 2010)

- effects on skeletal muscles - calcium transport and the sodium-potassium pump activity (Maughan, 2006)

- direct effects on a number of enzymes (Maughan, 2006)

Positive effects on athletic performance

Based on the above described effect it was found that multiple effects of caffeine might include that on athletic performance. A number of studies have therefore been conducted to determine it, mainly with regard to endurance performance. These studies were usually divided into continuous endurance test until exhaustion, rising stress tests and short-term endurance tests (Doherty \& Paul, 2004).

Several authors have described significant effect of caffeine on endurance performance at a certain VO2 peak level until exhaustion and in tests during the race (Cox et al., 2002; Graham \& Spriet, 1991; Graham \& Spriet, 1995; Kovacs et al., 1998; Pasman et al., 1995).

Although studies of the caffeine effect under a rising stress in the course of a short-term and intense performance also describe a positive effect, this does not tend to be as significant as the one produced by the above-mentioned studies dealing with performance under constant continuous stress (Anderson et al., 2000; Doherty \& Paul, 2004; Graham \& Spriet, 1996). 
Some studies did not confirm the positive effect of caffeine under endurance stress. These included especially running tests and rising stress tests (Burke \& Deakin, 2006).

Negative effects

Caffeine tends to be associated with numerous disorders although connection to this substance has never been established (Sokmen et al., 2008). Sensitive persons may display acute symptoms and the intake of high cafeeine dosages may lead to a number of undesirable effects including stomach discomfort, palpitations, tachycardia, headache, insomnia, muscle tremors, increased blood pressure, or dehydration (Jeukendrup \& Gleeson, 2010; Maughan, 2006). Caffeine is also linked to certain types of cancer, ventricular arrhythmia, damage to the fetus during pregnancy, menstrual problems, stomach ulcers (Toxnet et al., 1993). Not having been confirmed by studies involving humans, these conclusions, however, are rather vague (Sokmen et al., 2008; Toxnet et al., 1993). In any case, persons suffering from arrhythmia, or gastric ulcers are recommended to avoid caffeine intake (Toxnet et al., 1993). For a healthy adult individual, though, the consumption of 2-3 cups of coffee per day is considered a relatively harmless amount (Whitney \& Rolfes, 1993).

There has been conducted a number of studies dealing with caffeine, many of them confirming its positive impact on endurance performance. On the basis of these studies it may also be assumed that the longer the duration of the stress, the larger/more reliable the effect of caffeine use (Doherty \& Paul, 2004). Success rate of its use neverheless depends on many other factors, a fact which perhaps indicates further research potential, namely in the areas of different sources of caffeine, combination of caffeine with other nutrients and the amount of caffeine, where relevant data are still lacking. This fact was one of the reasons leading to the realization of this project. As was stated above the main goal of this study was to determine the effect of different caffeine dosages on time extension until exhaustion in a long-term endurance exercise and thus to attempt to cover one of these research gaps.

\section{MATERIAL AND METHODS}

The research was designed to determine the effect of different dosages of caffeine on long-term endurance performance. Based on the literature review, lower $\left(2 \mathrm{mg} \cdot \mathrm{kg}^{-1}\right)$ and higher $\left(7 \mathrm{mg}^{-\mathrm{kg}^{-1}}\right)$ dosages of caffeine were proposed. The research was conducted as an experiment, with the help of a placebo-controlled, double blind crossover study.

\section{Participants}

The most frequent consumers of caffeinated food supplements include endurance athletes (Burke \& Deakin, 2010). For this reason endurance athletes-cyclists were chosen for the research.

The experiment involved 10 male hobby cyclists $\left(30.3 \pm 5.8\right.$ y , BMI $=23.5 \pm 1.6, \mathrm{VO}_{2}$ peak $=56.9 \pm 6.6$ $\mathrm{ml} . \mathrm{kg}^{-1} \cdot \mathrm{min}^{-1}$ ) from the South Moravian region (Czech Republic) meeting the following characteristics: absence of medical contraindications excluding caffeine consumption and stress test completion. From a wider group of individuals those with the most similar characteristics were chosen. The tested persons were informed in advance of the testing protocol, which was duly approved by the Ethics Committee according to the Masaryk University Code. 


\section{Experimental design}

The experiment was conducted in the months of January and February 2013 within the range of 30 days.

Prior to the research stress test, a diagnosis of tested persons was performed to determine individual parameters (size of the load and the amount of caffeine).

I. There was carried out a diagnosis of the tested subjects using the method of bioelectrical impedance analysis. Its goal was to determine the basic anthropometric data and the bodily composition using the InBody 230 device (Biospace, Cerritos CA, USA). Based on the analysis all significant variations in the body composition were determined that could affect the outcome and also the exact amount of caffeine for the purposes of the experiment was established.

II. The method of functional stress diagnostics was applied, using the stress spiroergometry method until vita maxima through the Excalibur ergometer (Lode B.V., Groningen, Netherlands) with the metabolic unit being that of Metalyzer 3B (CORTEX Biophysik GmbH, Leipzig, Germany).

III. The resting heart rate upon awakening (HRrest) was determined. Measurement sessions were conducted a few times in the home of the tested persons as instructed by the expert and the results were processed to obtain the mean value.

From the obtained values of the maximum oxygen consumption $\left(\mathrm{VO}_{2}\right.$ peak) and the HRrest the individual load was calculated during the research stress test (level of pulse rate).

After completion of diagnostic tests, each tested person completed three experimental tests with the same protocol and under the same conditions, but always following consumption of a different amount of caffeine. The minimal rest intervals between each test were $72 \mathrm{~h}$. As instructed, tested persons followed diet recommendations requiring them to avoid foods containing caffeine. In addition, they were asked about their health and overall condition before each test.

\section{Testing procedures}

Each experimental test consisted of 1-h steady-state cycling on a static ergometer at a $70 \%$ VO2peak load which was immediately followed by a graded exercise test until exhaustion $\left(0.43 \mathrm{~W} \mathrm{x} \mathrm{s}^{-1}\right)$. Either a placebo or low dosage or high dosage of synthetic caffeine with 0.5 I water and the maximum of $0.5 \mathrm{mg} \cdot \mathrm{kg}^{-1} \mathrm{BM}$ dosage of carbohydrate gel were administered 70 minutes prior to the test. Besides other indicators the final time achieved was observed. The test was completed using the same device as the input diagnostic test.

\section{Data analysis}

The main indicator observed was the final time. The result was presented as the average time with a deviation for each dosage of caffeine. The resulting times for different dosages were then compared and statistically processed. To determine significance the statistical method of paired $t$-tests was utilized. The significance level was set at $p<0.05$.

The obtained data were processed using the Exel (Microsoft, Redmond WA, USA) and Statistica 12 (Statsoft, Tulsa OA, USA) programmes. 


\section{RESULTS}

Total exercise time was significantly $(p<0.05)$ extended by the high dosage compared with a placebo (extension of $34.2 \mathrm{~s}, 0.77 \%$ enhancement). A significant $(p<0.05)$ extension of the total exercise time was also observed under the high dosage compared with low dosage (extension of $33.8 \mathrm{~s}, 0.76 \%$ enhancement). No statistically ( $p=0.97$ ) significant differences were observed between the low dosage and a placebo (extension of $0.4 \mathrm{~s},<0.01 \%$ enhancement). Summary results in figures can be seen in Table 1 while representative results for each test are shown in Figure 1. The standard deviation is greatest with the results generated under the low dosage and a significantly larger standard deviation also results from the high dosage in comparison with the placebo standard deviation (Table 1, Figure 2).

Table 1. Summary results

\begin{tabular}{|c|c|c|c|c|}
\hline $\begin{array}{c}\text { Dosage } \\
{\left[\mathrm{mg.kg}{ }^{-1}\right]}\end{array}$ & $\begin{array}{c}\text { mean } \\
{[s]}\end{array}$ & $\begin{array}{c}\text { stdev } \\
{[\mathrm{s}]} \\
\end{array}$ & $\begin{array}{c}\text { enhancement } \\
{[\%]}\end{array}$ & $\begin{array}{c}\text { p value } \\
\text { (t-test) }\end{array}$ \\
\hline 0 & 4431,10 & 69,61 & - & $\mathbf{0}-\mathbf{2}: 0,9723$ \\
\hline 2 & 4431,49 & 81,21 & $<0,01 \%$ & $2-7: 0,0123$ \\
\hline 7 & 4465,30 & 76,77 & $0,77 \%$ & 0-7:0,0096 \\
\hline
\end{tabular}

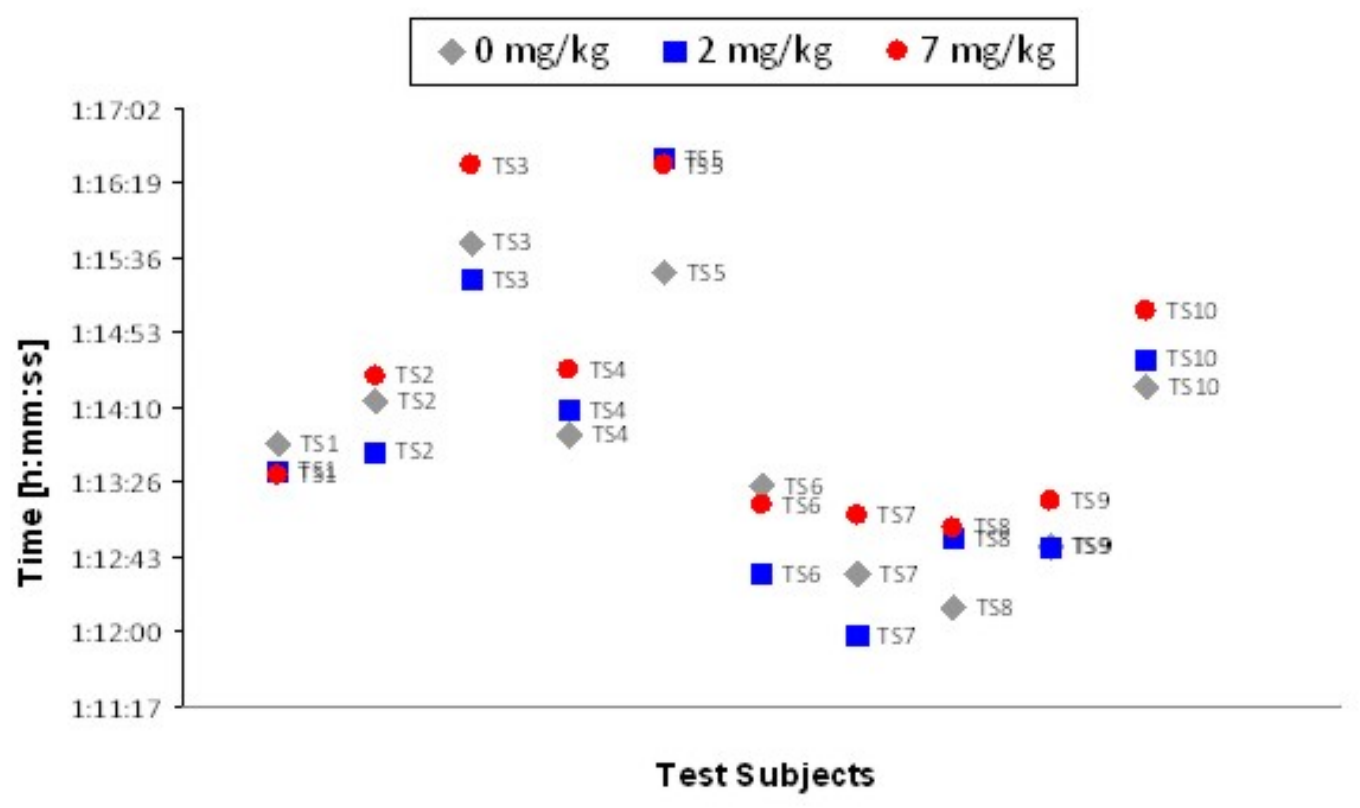

Figure 1. Results of the completed test times 


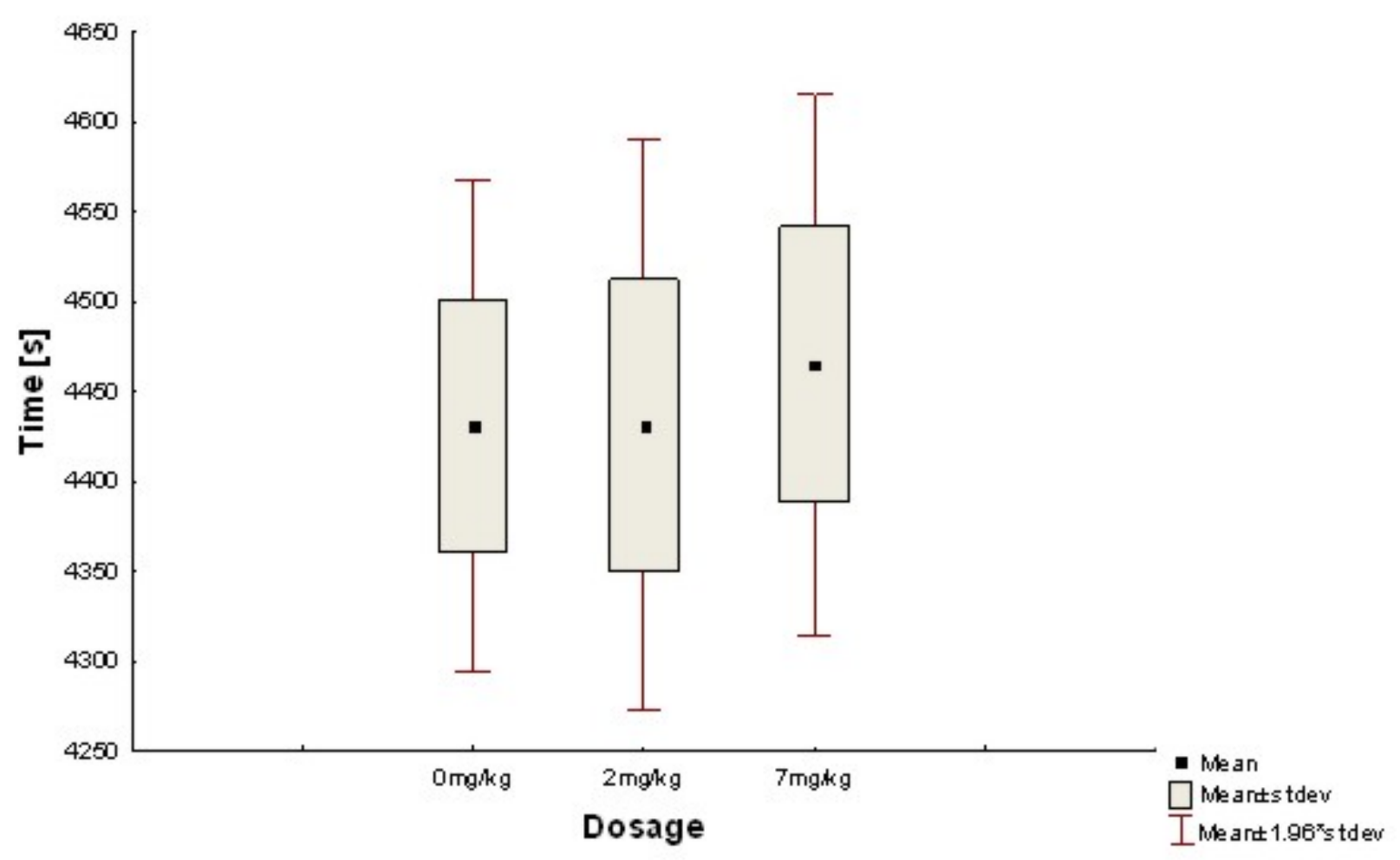

Figure 2. Box plots to compare test results

\section{DISCUSSION}

The aim of this study was to determine the effect of various caffeine dosages on time extension until exhaustion in a long-term endurance exercise. The experiment has brought the following results. The load was best handled by the tested persons when using the high dosage, while the placebo and low dosage produced almost identical results of a slight positive effect of caffeine. These results support the general claim that caffeine can have a positive effect on endurance performance (Baechle \& Earle, 2008; Kenney et al., 2012). They do not, however, confirm the statement that a high dosage produces a similar or even lower effect when compared with the low dosage (Bruce et al., 2000; Cox et al.; 2002; Graham \& Spriet, 1995; Pasman et al., 1995). The low dosage was essentially ineffective. Naturally these results do not undermine the general theory, but rather point to the inconsistency of the caffeine effect. This fact is confirmed by a larger standard deviation in the results for lower and higher dosages of caffeine, which points to a greater variety of results compared to those produced by a placebo.

Although the research was systematic and planned so as to maintain validity, the results could have been influenced by other factors, especially those that could not be checked in advance (slight variations in the physical and mental condition of the tested persons, hidden internal weakness that might arise between testing sessions, and other). The number of tested persons (10) was the maximum possible number given the finance, material and space available. The obtained result therefore cannot be used to change the existing theory, but rather to point out a possible inconsistency in the research results of this substance.

From a practical point of view and based on the research results it may be said though that the effect of this substance on a long-term endurance performance under the rising stress conditions and under a lower 
dosage in particular may not always be positive with cyclists. This depends on a number of factors such as the organism's response to the substance, its prior consumption, overall condition of the organism, the intake time, dosage size, source of intake, load type, intensity and duration, etc. (Benardot, 2000; Burke \& Deakin, 2010; Graham et al., 1998; Jeukendrup \& Gleeson, 2010; Kenney et al., 2012; Spriet, 1995). Despite the fact that a lot of research dealing with caffeine has been conducted, the area still offers vast research potential especially due to the variety of intervening factors. The comprehensive information on this drug is therefore needed both in the sports arena and outside of it.

\section{CONCLUSIONS}

The experiment does not confirm a general theory stating that there is no significant difference in the enhancement of endurance performance as produced by the low and high caffeine dosage. A positive effect of caffeine on long-term endurance in hobby cyclists was observed only after ingestion of a high dosage. Compared with a placebo, a low dosage failed to show any ergogenic effect. This result, however, should not be generalized, rather it should be viewed as showing ambiguous effects of this substance.

\section{REFERENCES}

1. Ais Sports Nutrition. (2012). Ais website fact sheet - ais sports supplement program CAFFEINE . Retrieved from Australian Sport Comission website: http://www.ausport.gov.au/_data/assets/pdf_file/0003/469650/Caffeine_11_website_fact_sheet.pdf

2. Anderson, M. E., Bruce, C. R., Fraser, S. F., Stepto, N. K., Klein, R., Hopkins, W. G., \& Havley, J. A. (2000). Improved 2000-meter rowing performance in competitive oarswomen after caffeine ingestion. Int J Sport Nutr Exerc Metab, 10(4), pp.464-475.

3. Baechle, T. R., \& Earle, R. W. (c2008). Essentials of strength training and conditioning (3rd Ed.). Champaign, III: Human Kinetics.

4. Benardot, D. (c2000). Nutrition for serious athletes: [an advanced guide to foods, fluids, and supplemants for training and performace]. (pp. 133-134) Champaign: Human Kinetics.

5. Bruce, C. R., Anderson, M. E., Fraser , S. F., Stepto, N.K., Klein, R., Hopkins, W. G., \& Hawley, J. A. (2000). Enhancement of 2000-m rowing performance after caffeine ingestion. Med Sci Sports Exerc, 32(11), pp.1958-1963.

6. Burke, L. \& Deakin, V. (2006). Dose-response studies of caffeine on exercise performance using placebo-controlled crossover. [onlinePDF]. Australia: McGraw-Hill. Retrieved from http://www.ausport.gov.au/_data/assets/pdf_file/0004/145174/T16.4Caffeine.pdf

7. Burke, L., \& Deakin, V. (2010). Clinical sports nutrition (4th Ed.). Sydney: McGraw-Hill Companies.

8. Cox, G.R., Desbrow, B., Montgomery, P.G., Anderson , M. E., Bruce, C. R., Macrides,... Burke, L. M. (2002). Effect of different protocols of caffeine intake on metabolism and endurance performance. J Appl Physiol, 93(3), pp.990-999.

9. Doherty, M., \&Paul, M. S. (2004). Effects of caffeine ingestion on exercise testing: A meta-analysis. Int J Sport Nutr Exerc Metab, 14, pp.626-646.

10. Graham, T. E., \& Spriet, L. L. (1991). Performance and metabolic responses to a high caffeine dose during prolonged exercise. J Appl Physiol, 71(6), pp.2292-2298.

11. Graham, T. E., \& Spriet, L. L. (1995). Metabolic, catecholamine, and exercise performance responses to various doses of caffeine. J Appl Physiol, 78(3), pp. 867-874.

12. Graham , T. E., \& Spriet, L. L. (1996). Caffeine and exercise performance. SSE\#60, 9(1). 
13. Graham, T. E., Hibbert, E., \& Sathasivam, P. (1998). Metabolic and exercise endurance effects of coffee and caffeine ingestion. J Appl Physiol, 85, pp.883-889.

14. Greenwood, M., Kalman, D., \& Antonio, J. (c2008). Nutritional supplements in sports and exercise. (pp. 349-350) Totowa, N.J.: Humana Press.

15. Jeukendrup, A., \& Gleeson, M. (c2010). Sport nutrition: an introduction to energy production and performance (2nd Ed.). Champaign, III.: Human Kinetics.

16. Kenney, W., Wilmore, J., Costill, D., \& Wilmore, J. (c2012). Physiology of sport and exercise (5th Ed.). Champaign, III.: Human Kinetics.

17. Kovacs, E.M.R., Stegen, J.H.C.H., \& Brouns, F. (1998). Effect of caffeinated drinks on substrate metabolism, caffeine excretion, and performance. J Appl Physiol, 85(2), pp.709-715.

18. Lieberman, H. R. (2003). Nutrition, brain function and cognitive performance. Appetite, 40, pp.245254.

19. Maughan, R. (c2006). Výživa ve sportu: přiručka pro sportovní medicínu. Praha: Galén, pp. 220223.

20. Pasman , W.J., Van Baak, M.A., Jeukendrup , A.E., \& De Haan , A. (1995). The effect of different dosages of caffeine on endurance performance time. Int J Sports Med, 16(4), pp. 225-230.

21. Sökmen, B., Armstrong, L., Kraemer, W.J., Casa, D.J., \& Dias, J.C. (2008). Caffeine use in sports: Considerations for the athlete. J Strength Cond Res, 22(3), pp.978-986.

22. Spriet, L.L. (1995). Caffeine and performance. Int J Sport Nutr, 5 Suppl., pp.84-99.

23. Toxnet. (n.d.). Caffeine> human health effect. U.S. National Library of Medicine, Retrieved from http://toxnet.nlm.nih.gov/cgi-bin/sis/search/r?dbs hsdb:@term @rn 58-08-2

24. Whitney, E. \& Rolfes, S. (c1993). Understanding nutrition (6th Ed.). Minneapolis: West Publishing. 